\title{
Design and Verification of On-Line Monitoring \& Controlling System of Tensioner
}

\author{
http://dx.doi.org/10.3991/ijoe.v9i2.2597 \\ M. J. Li ${ }^{1}$, M. L. Duan ${ }^{1}$, L. Lin ${ }^{1}$, J. L. Zhang ${ }^{2}$, M. Ye ${ }^{1}$, G. M. Chen ${ }^{1}$ \\ ${ }^{1}$ China University of Petroleum, Beijing, China \\ 2 Zhongyuan Oil Field, Puyang, Henan, China
}

\begin{abstract}
Tensioner for deep water pipe-laying vessel is a type of engineering equipment that is applied in sub-sea pipeline laying. Based on the designed tensioner body for $\mathrm{S}$ lay vessel, with the capacity of $200 \mathrm{t}$ and can meet the requirements of $3000 \mathrm{~m}$ water-depth pipe-laying, the corresponding monitoring and controlling system need to be designed. Firstly, the programs of on-line monitoring and controlling system are proposed, and then the software and hardware of the system are designed. In addition, the manmachine interaction interface of the system is developed. This research could provide the guidance for the design of the on-line monitoring and controlling system of 200t tensioner. The test is carried out to verify the functions of the designed on-line monitoring \& controlling system. The test results show that the designed system is reliable and also have good maneuverability.
\end{abstract}

Index Terms-Tensioner, on-line monitoring \& controlling system, man-machine interaction interface, testing.

\section{INTRODUCTION}

Offshore oil \& gas resources accounted for the 34\% of global oil \& gas resources [1]. With the growth of energy consumption and the shortage of land oil \& gas reserves, to improve the pace of offshore oil \& gas development becomes the main task [2, 3, 4]. Pipeline is the hub to connect subsea wells and Floating Production System and it is the indispensable part of deep sea oil \& gas development $[5,6]$. Tensioner is one of the most important components of J-lay or S-lay system [7, 8, 9]. In the pipelaying process, pipeline enter into the water though the stringer at the stern of the pipe-laying vessel, there is the long distance pipeline from the stern to the seabed which called suspended segment and motions in heave direction of the vessel could cause the changes of pipeline length and then result in the variation of the stress of pipeline. As the vessel moves up along with the wave, the suffered tension of the tensioner which induced by self-weight of pipeline will increase and the pipeline may be damaged if the stress exceeds the allowable one. As the vessel moves down, the tension will decrease but the bending stress will increase, the plastic deformation may occur if the bending stress beyond the yield one [10, 11, 12 ]. In order to keep the tension of the pipeline unchanged during the pipelaying process, tensioner is needed to ensure the safety of the process.

The mechanical body of the tensioner for S-lay vessel is designed to meet the requirements of development of the South China Sea $[13,14]$. The designed tensioner could provide the $200 \mathrm{t}$ tension and can be used in $3000 \mathrm{~m}$ water- depth pipe-laying process. The Maximum lowering speed is $40 \mathrm{~m} / \mathrm{min}$, and the maximum recovering speed is 20 $\mathrm{m} / \mathrm{min}$, and has ability of 4-60 in diameter pipe-laying. Based on the designed tensioner body, investigate on the corresponding on-line monitoring and controlling system of the tensioner is presented in this paper. Firstly, the programs of on-line monitoring and controlling system are proposed, and then the software and hardware of the system are designed. In addition, the man-machine interaction interface of the system is developed.

\section{Design Of Tensioner Mornitoring And CONTROLLING SYSTEM}

The monitoring system of tensioner involving control, testing and communication technology, it is a complex system. Five subsystems are included: Center Control System (CCS), Track Drive subsystem, Track Clamping Subsystem, Track Adjusting Subsystem and Hydraulic Power Unit (HPU) Subsystem. Advanced control technical program is adopted to form the coordination of the various systems based on fieldbus, which is combining intelligent instrumentation and remote IPC $[15,16]$. Monitoring and controlling system mode is shown in Figure 1.

(1) The main feature of host computer of CCS is to control the tensioner remotely in a centralized control room. The operator must have administer permission for setting values of tensioner on-line, monitor, control and alarm the processing as well.

(2) The Track Driving Subsystem drives the motors in accordance with the expected tension value and pipelaying speed target value assigned by the host computer real-timely. A constant tension control device and the inverter-fed motors consist of a closed-loop control system. The speed and direction of the track driving motors can be adjusted from instant to instant.

(3) With the control action of Track Clamping Subsystem, the clamping force of pipeline maintains a relatively

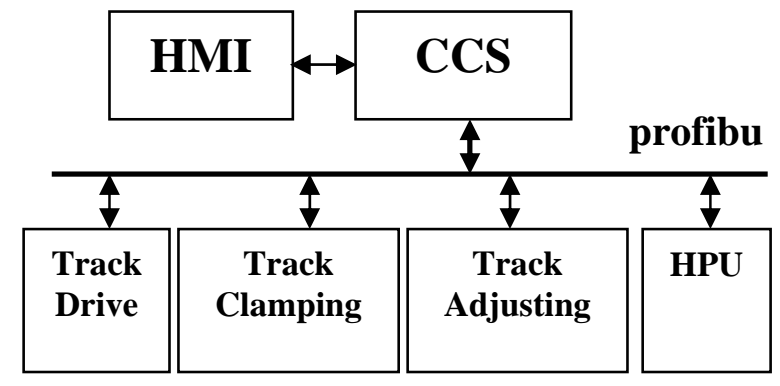

Figure 1. Mode of monitoring system 
constant value according to the target value. The hydraulic suspension system and clamping system work together when tracks clamp the pipeline.

(4) Track Adjusting Subsystem adjusts the height level and inclination angle of the tracks on the basis of the value given by the host computer so as to meet the system requirements.

(5) The Hydraulic Station Control Subsystem is in charge of the management of pumping station, including single/ multi-machine startup and shutdown, hydraulic efficiency flow control, constant pressure regulation, as well as oil temperature monitoring function.

To meet the pipe-laying process requirements, the parameters such as hydraulic pressure and laying speed of tensioner are scanned from time to time and can be reset at any stage of the work. Tensioner will keep working according to the new parameters as soon as it is set. Basic control flow of the monitoring system is shown in Figure 2.

III. HARdware And Software Design Of Tensioner MONITORING AND CONTROLLING SYETEM

\section{A. Hardware Design}

As a control center, BECKHOFF company's C3350 IPC [17] is the master station of system and communicates with each underlying slaves via the fieldbus.

PC Profibus Card FC3101 placed in C3350 IPC, communicates with profibus bus couplers BK3120 via Profibus-DP. The scene underlying equipment, such as intelligent instruments, sensors, inverters, proportional valves, reversing valves is connected to the corresponding types of I/O modules. Track Drive subsystem, Track Clamping Subsystem, Track Adjusting Subsystem and Hydraulic Power Unit (HPU) Subsystem are as slaves of profibus individually.

All control command data collected on the tensioner console is transmitted to the IPC via the corresponding input ports. IPC communicates via the fieldbus with the field slaves, monitoring and controlling the bottom facilities such as intelligent instruments, sensors and other modules.

The main function of monitoring and control system console is to provide an interface for tensioner manual controlling, such as system operating, emergency stop, the brake off, et al. At the same time, through the display panel we can monitor the manual adjustment process of the hydraulic cylinder position and the pipe-laying process using the tensioner.

\section{B. Software Design}

\section{1) Software compiler environment settings}

The number of control points of deep-water pipe-laying tensioner system is up to more than one hundred. MCGS configuration software combines with TwinCAT software PLC can makes up for disadvantages of traditional PLC well.

TwinCAT software PLC (Soft PLC), which provides the same functionality as ordinary PLC, provides various advantages of the PC environment as well. Chinese configuration software Monitor and Control Generated System (MCGS) [18], used in generating computer moni-

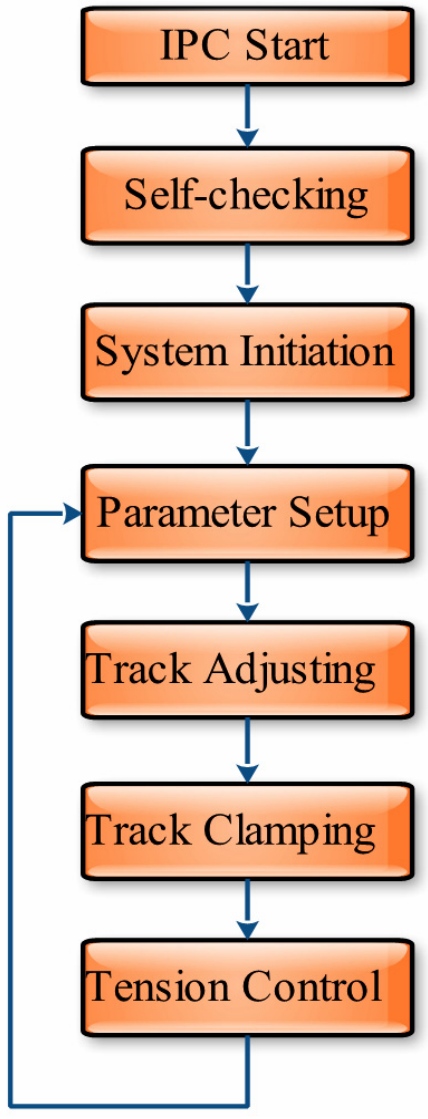

Figure 2. Flow chart of monitoring system
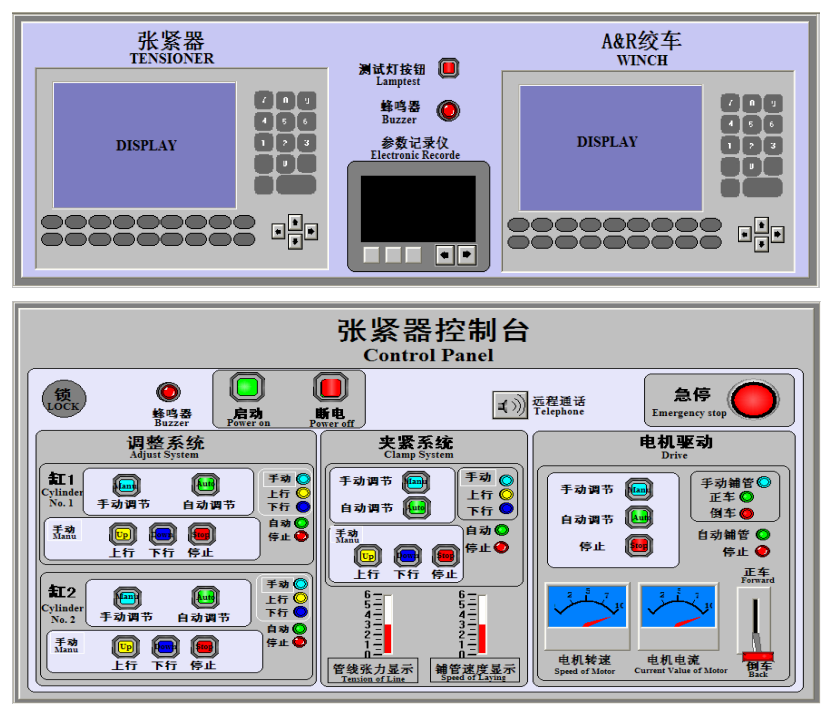

Figure 3. Control panel of field operating desk

toring and controlling system rapidly ${ }^{[12]}$, has characteristics of good real-time, powerful parallel processing ability and vivid picture features. Meanwhile, MCGS is with an open architecture and fully supports for the OPC standard.

\section{2) Software communication mode}

MCGS and TwinCAT soft-PLC communicates with each other complying with OPC software standard [19]. They all have OPC standard interface, the two can connect and realize the data exchange so easily as to accomplish the on-site data processing and equipment controlling on line. 
BECKHOFF Profibus bus is a communication link between the host computer and the on-site equipment. Bus terminal as an open and flexible I/O system, simplify the system architecture and improve communication speed.

\section{HMI DEVELOPMENT}

Remote IPC enable the tensioner to have remote monitoring function. Operators set up parameters, send control commands, monitor state and storage data by controlling the panel or touch screen. The HMI of the tensioner remote monitoring system is developed adopting MCGS.

The main function of HMI is parameter settings and status monitoring.

Parameter settings: set the cylinder height and inclination parameter; set the pipeline parameter and target clamping force parameters; set the hydraulic pressure, the tension of the drive system, pipe-laying speed, dead band parameter, et al. It is shown in Figure 4.

Status monitoring: monitor tensioner and pipeline state during pipe-laying process; display goal setting value and real-time value so that the operator can determine the reliability of the work. It is shown in Figure 5, 6.

\section{Data Display And Storage Of Monitoring And CONTROLLING SYSTEM}

Besides has the function of control the hydraulic system and the drive system, the monitoring and controlling system also has the function of on-line monitoring the running state (pressure, pipe-laying speed and et, al) of the system, and the state will display on the HMI. The key parameters during the pipe-laying process can be stored for subsequent analysis.

MCGS default using Microsoft Access database as a historical inventory database, and using database technology to manage and maintain inventory data. The path and the file name of Inventory database can be set in the properties of main control window. Timing storage technique is adopted to store the data automatically during the pipe-laying process.

After the MCGS successful communicate with the soft PLC though OPC, MMI can display the data which comes from the out-put value of the program on-line.

\section{VERIFICATION OF ON-LINE MONITORING\& CONTROLLING SYSTEM}

\section{A. Structure of testing stand}

Two motors are coaxial mounted, as one simulates the vessel response of the wave, the other works as the driving motor. When motor No.1, viz. vessel simulator' s rotate speed changes, the driving motor would follow rapidly to rotate forward or reverse to eliminate the torque caused by the difference in speed ( measured by torque sensor). The structure is shown in Figure 7.

\section{B. Control algorithm}

The driving motor is controlled with PID algorithm. A PID controller collects real-time torque signal. By comparing the signal with reference value given by the host computer, PID controller will output a driving speed to make both of the motors run at the same speed. Torque also maintains within the permissible range.

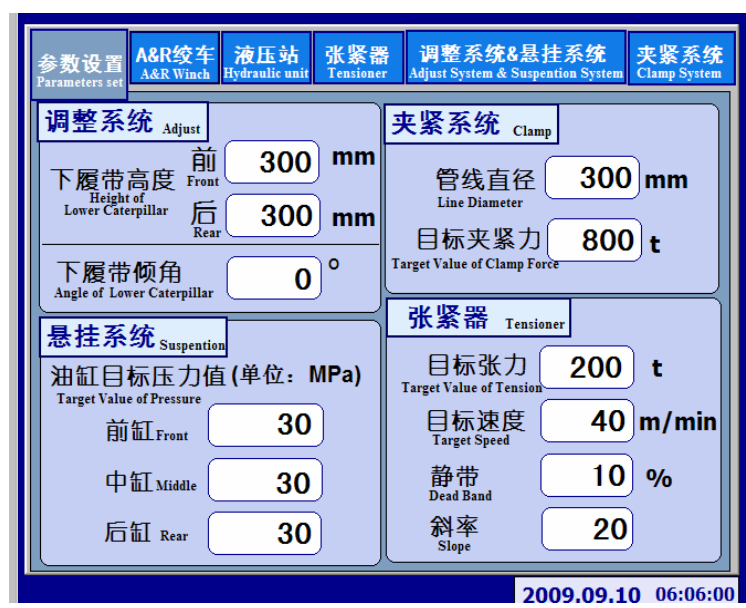

Figure 4. Interface of parameter setting

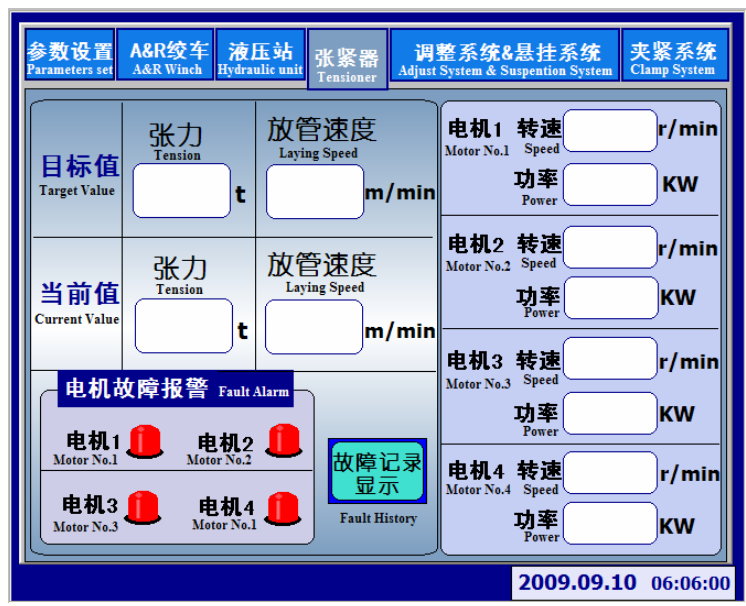

Figure 5. Monitor interface of driving system

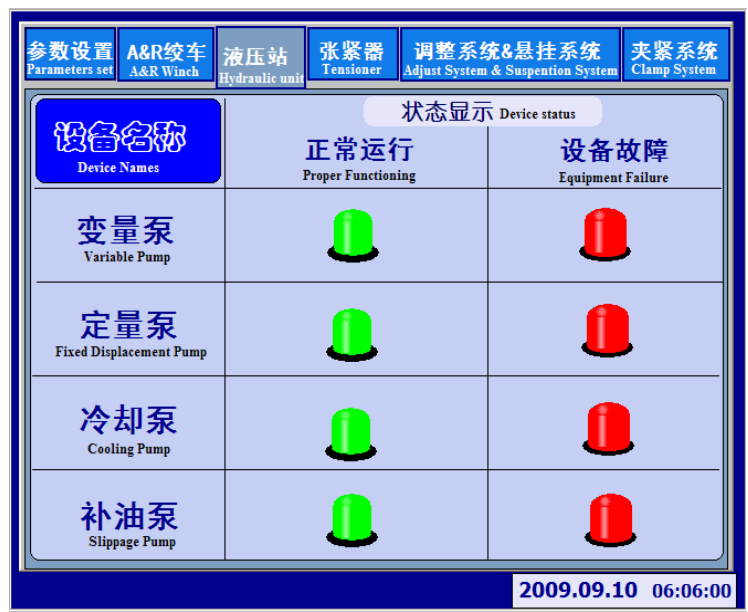

Figure 6. Monitor interface of Hydraulic unit

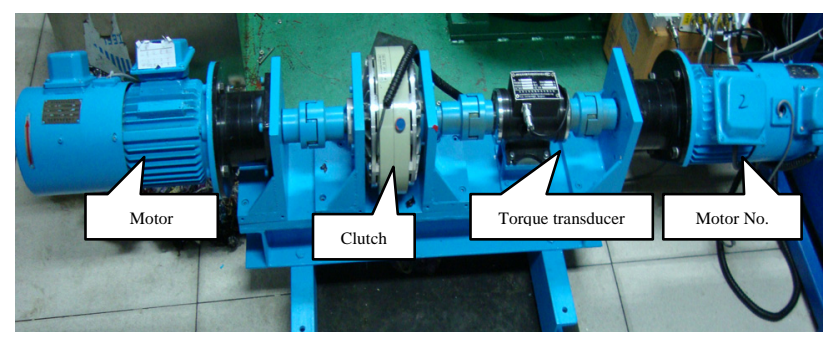

Figure 7. Photo of driving function testing stand 


\section{Analysis of test results}

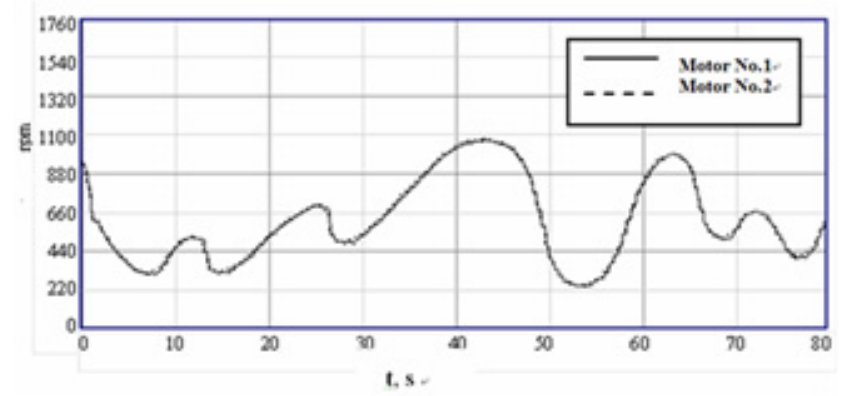

Figure 8. Speed curve of dual-motor

Motor No.2, the driving motor, is running in the wake of the speed of motor No.1 under the action of the control system. Figure 8 shows that the two motors are operating with perfect driving accuracy and good synchronization.

\section{VII. CONCLUSION}

In this paper, the hardware and software of the monitoring and controlling system for pipe-laying tensioner is designed. As a control center, Beckhoff IPC C3350 communicates with the underlying intelligent instruments by profibus. The hardware of the monitoring and controlling system is configured, synchronously, the whole control processes is determined based on the characteristics of tensioner's hydraulic as well as the drive system. Otherwise, the software compiler environment is established and tensioner monitoring interfaces are developed based on MCGS. The test results shows that the designed on-line monitoring \& controlling system of the tensioner is reliable and has good maneuverability.

\section{ACKNOWLEDGEMENT}

The authors are grateful for the financial support from the China National 863 Hi-tech Research and Development Program: Research on deep-water subsea pipelinelaying Key Technology (Grant No. 2006AA09A 105-2), the National Basic Research Program of China (Grant No. 2011CB013702).

\section{REFERENCES}

[1] Jin, Q.; Zhang, G. Z.; (2005). The present situation and prospect of world ocean oil \& gas development [J], International Petroleum Economics, 25(6), pp43-44, ISSN: 1004-7298.

[2] Bourgeois, T. M.; Godfrey, D. G.; Bailey, M. J. ; (1998). Race on for Deep-water Acreage, 3500-Meter Depth Capability. Offshore International Edition ,58(10),pp40-41.

[3] Paul, W.; Mark, G. R.; Barry C. M.; (1998). Evaluating the Petroleum Systems of the Northern Deep Gulf of Mexico through Integrated Basin Analysis: An Overview, A A PG Bulletin, 82(5), pp865-877.

[4] Jennifer, H; (2003) Deep-water Discovery Survey Shows Increase from 2001. Offshore International Edition, 63(1), pp36-40.

[5] Mekha, B. B.; Independence Hub Flow-line SCRs: Design, Fabrication, and Installation Challenges[C], Offshore Technology Conference, 30 April-3 May 2007, Houston, Texas. ISBN:978-155563-254-0.

[6] Gore, C.T.; Mekha, B.B.; Common Sense Requirements (CSRs) for Steel Catenary Risers (SCR)[C], Offshore Technology Confer- ence, 6 May-9 May 2002, Houston, Texas, ISBN: 978-1-55563249-6.

[7] Wang, L.; Zhang, X. F.; Wei L.V.; Yue, Q. J.; He,N.; Zhou, L.; Conceptual Analysis of Stinger For Ultra-deepwater S-lay, Third ISOPE International Deep-Ocean Technology Symposium, June 28 - July 1, 2009 , Beijing, China.

[8] Chui, H. Jo; Limitation And Comparison of S-Lay And J-Lay Methods[C], The Third International Offshore and Polar Engineering Conference, June 6 - 11, 1993 , Singapore.

[9] Sriskandarajah,T. ; Ragupathy,P.; Anurudran, G. ; Wilkins, R.; Design Considerations in the Use of Pipe-In-Pipe Systems for $\mathrm{Hp} / \mathrm{Ht}$ Subsea Pipelines[C],The Eleventh International Offshore and Polar Engineering Conference, June 17 - 22, 2001 , Stavanger, Norway.

[10] Mitchell, M. R.; Dessureault, J. G.; (1992). A constant tension winch design and test of a simple passive system [J]. Ocean Engineering, 5(19), pp 489-496, ISSN: 0029-8018.

[11] Perinet, D.; Frazer, L.; Offshore Technology Conference, 5-8 May 2008, Houston, Texas, USA, ISSN: 978-1-55563-224-3.

[12] McPhail, J. F.; Finn, L. D.; Rohmaller, P. L.; Okaro, J.C.;(1974), Measuring Construction Stresses In Offshore Pipeline[J], Journal of Petroleum Technology, 26(3), pp 261-268, ISBN:0369-9013.

[13] Zhang, J. L,; Wang, X. B. Lin, L.; Zhao, D.Y.; Zhong, C. T.; (2008). Analysis of tension system of tensioner for pipe-laying vessel [J]. Petroleum Machinery, 36 (9), pp167-169.

[14] Zhang, J. L.; (2010).Research on Key techniques in Mechatronic System of Tensioner for Deep Water Pipe-laying Vessel [D].Beijing: China University of Petroleum.

[15] Liu, M. J.; (2006). Open architecture soft PLC based on PC. Machine Tool Electric Apparatus, 33(1), pp5-8,ISSN: 1004-0420.

[16] Liu, W. W.; (2009). Research on soft PLC technology. Heilong jiang Science and Technology Information, (10), pp32, ISSN: 1673-1328.

[17] http://www.beckhoff.com.cn.

[18] Yuan,X. Y.;(2003).The configuration control technology. Beijing: Publishing House of Electronics Industry of China, ISBN: 750539018X.

[19] Chen, Z. P; (2008). Fieldbus and industrial network control technology. .Beijing: Publishing House of Electronics Industry of China. ISBN: 9787121064357.

\section{AUTHORS}

M. J. Li is with China University of Petroleum-Beijing, Beijing, China. (mingjie.l@hotmail.com).

M. L. Duan is the professor of College of Mechanical and Transportation Engineering, China University of Petroleum-Beijing, Beijing, China (mlduan@cup.edu.cn).

L. Lin is the professor of China University of Petroleum-Beijing, Beijing, China. (cmeelin@cup.edu.cn).

J. L. Zhang is with Zhongyuan Field, Puyang, China. (30015023@qq.com).

M. Ye is with China University of Petroleum-Beijing, Beijing, China. (ymzhangquan@163. com).

G. M. Chen is with China University of PetroleumBeijing, Beijing, China. (804432024@qq.com)

The research is supported by the China National 863 Hi-tech Research and Development Program: Research on deep-water subsea pipelinelaying Key Technology (Grant No. 2006AA09A 105-2), the National Basic Research Program of China (grant No.2011CB013702). It is an extended and modified version of a paper presented at the International Conference on Mechanical Engineering, Automation and Material Science (MEAMS2012), held 22-23 December 2012, Wuhan, China. Received 19 March 2013. Published as resubmitted by the authors 25 April 2013. 